\title{
Hypoglycemic effect of instant aloe vera on the diabetic rats
}

\author{
${ }^{1}$ Riyanto and ${ }^{2 *}$ Wariyah, Ch. \\ ${ }^{I}$ Department of Agrotechnology, Faculty of Agroindustry, Mercu Buana University of Yogyakarta, Jl. Wates \\ Km 10 Yogyakarta 55753, Indonesia \\ ${ }^{2}$ Department of Food Technology, Faculty of Agroindustry, Mercu Buana University of Yogyakarta, Jl. \\ Wates Km 10 Yogyakarta 55753, Indonesia
}

\author{
Article history: \\ Received: 3 August 2017 \\ Received in revised form: 27 \\ August 2017 \\ Accepted: 28 August 2017 \\ Available Online: 2 \\ September 2017
}

Keywords:

Flavonoid,

Antioxidative-activity,

Blood-glucose

DOI:

https://doi.org/10.26656/fr.2017.2(1).119

\begin{abstract}
Instant aloe vera contains phenolic compounds which has antioxidative activity. However, this product is hygroscopic and damaged easily during storage. The critical condition of the instant occurs at the moisture content of $12.52 \pm 0.24 \%(\mathrm{wb})$. Increasing the moisture content could accelerate oxidation of the phenolic compounds, thus decrease the antioxidative activity. Previous research showed that the antioxidative activity of instant aloe vera could lower the blood glucose. The purpose of this study was to evaluate the hypoglycemic activity of instant aloe vera during storage until the critical condition. The hypoglycemic effect was determined with the in vivo method using diabetic Wistar rats as experimental animals. The diabetic rats were fed with a standard feed combined with instant aloe vera which has been stored at various storage time i.e. 0, 2, 4, 6, 8 weeks and used normal rats fed without instant aloe vera as a control. The blood glucose was analyzed every week until 4 weeks. The research showed that the diabetic rats fed with standard feed without instant aloe vera had high blood glucose $(219.40 \mathrm{mg} / \mathrm{dL})$ after 4 weeks treatment. Otherwise, the blood glucose of diabetic rats fed with instant aloe vera decreased from $214.00 \mathrm{mg} / \mathrm{dL}$ to $97.57 \mathrm{mg} / \mathrm{dL}$ after 4 weeks.
\end{abstract}

\section{Introduction}

Instant aloe vera was made from aloe vera leaves and was processed by microencapsulation using spray dryer and maltodextrin as an encapsulating agent. Instant aloe vera contains phenolic compound of $1.64 \pm 0.09 \mu \mathrm{g} / \mathrm{g}$ dry matter (Wariyah and Riyanto, 2015). According to Sultana and Anwar (2008), the phenolic compounds in aloe vera gel are flavonoid i.e kaempferol, quercetin, and myricetin of about 257.70; 94.80 and $1283.50 \mathrm{mg} / \mathrm{kg}$, respectively. Flavonoids have an antioxidative activity indicated by their ability to capture free radicals of DPPH (1,1-Diphenyl-2-picrylhydrazyl) (Hu et al., 2005). Joseph and Raj (2010) stated that the bioactive substances in aloe vera can lower blood glucose. Jasmine and Daisy (2007) found that methanol soluble extract of Eugenia jambolana, which also contains flavonoids, could lower blood glucose, so the hypoglycemic effect is estimated to be related to the flavonoids. Yagi et al. (2009) proved that consumption of aloe vera fraction about $10 \mathrm{ppm}$ over a period of 6 weeks, could lower the blood glucose of the experimental animals.

The processing of instant aloe vera used aloe vera powder (dried aloe vera) as a raw material and was done in consecutive stages i.e. reconstituting aloe vera powder using aquadest at a ratio of $1: 120(\mathrm{w} / \mathrm{v})$, filtering the solution, and then maltodextrin added as an encapsulating agent. The solution was fed into a spray dryer. Wariyah and Riyanto (2015) showed that instant aloe vera had high antioxidative activity and the ability to capture free radicals with a percentage of RSA (Radical Scavenging Activity) was about $16.34 \pm 1.14 \%$ (fresh instant) and $2.34 \pm 0.37 \%$ (instant at critical condition), and the inhibition of lipid peroxidation was $39.34 \pm 1.58 \%$ (fresh instant) and $21.34 \pm 0.16 \%$ (instant at critical condition). The antioxidative activity of instant aloe vera decreased during storage caused by contact with light, heat, and oxygen, which accelerated oxidation reaction of flavonoid (Özkan and Bilek, 2014). 
Decreasing of the antioxidative activity of instant aloe vera could affect the hypoglycemic activity because it relates to the free radical neutralization by antioxidant. According to Barlett and Eperjesi (2008), hyperglycemia and diabetes cause an increase in free radical or ROS (Reactive Oxygen Species) i.e. superoxide, hydrogen peroxide and singlet oxygen. ROS is capable of damaging lipid membranes, proteins, nucleic acids, and carbohydrates via oxidation, resulting in the formation of cytotoxic chain reactions. Therefore, an antioxidant that may neutralize free radicals effectively is needed. The purpose of the study was to evaluate the hypoglycemic activity of instant aloe vera during storage until reached critical condition.

\section{Materials and methods}

\subsection{Materials}

Aloe vera leaves (Aloe vera var. chinensis) with harvesting age of $1.5-2.0$ years were obtained from the Loano District in the Purworejo Regency, Central Java Province, Indonesia. Maltodextrin DE 20 as an encapsulating agent was purchased from Brataco Chemika and sodium chloride for adjusting relative humidity during storage of the instant from Merck. Plastic film for packaging of aloe vera instant used the High Density Polyethylene (HDPE) with $0.80 \mathrm{~mm}$ thickness was obtained from "40" store at Yogyakarta, Indonesia.

\subsection{Methods}

Aloe vera leaves were processed into powder before microencapsulated into instant and the processing of powder referred to Wariyah and Riyanto (2011). Microencapsulation of aloe vera powder into the instant referred to Wariyah and Riyanto (2016) and prepared as follows: aloe vera powder was reconstituted by using distilled water at ratio of $1 / 120(\mathrm{w} / \mathrm{v})$ and then mixed with $7.5 \%(\mathrm{w} / \mathrm{v})$ maltodextrin with constant stirring using a magnetic stirrer (Stir plate Nuova II) at $700 \mathrm{rpm}$ for 45 minutes. The solution was fed into the spray dryer (Lab Plan SD-05) at an inlet temperature of $130^{\circ} \mathrm{C}$ and an outlet temperature of $103^{\circ} \mathrm{C}$, an air flow rate of $50 \mathrm{~m}^{3} /$ $\mathrm{h}$, and a solution flow rate of $350 \mathrm{~mL} / \mathrm{h}$. The powders (instants) obtained were packaged in plastic film with 0.80 thickness and stored at various storage time of : 0 , $2,4,6,8$ weeks, at a relative humidity of $75 \%$ (adjusted with $\mathrm{NaCl}$ ) and temperature of $25^{\circ} \mathrm{C}$. The hypoglycemic effect was determined by the in vivo method (Kabir et al., 1998) using Wistar rats with an age of $3-4$ months and a weight of between $240-260 \mathrm{~g}$. The rats were obtained from the Integrated Research Centre Labs., Gadjah Mada University of Yogyakarta, Indonesia.

\subsection{Determination of instant aloe vera intake for rats}

Each of sample instant aloe vera with different storage time was used as animal feed combined with standard feed (Reeves et al., 1993). The diabetics rats were prepared by alloxan induction during 5 days as much as $125 \mathrm{mg} / \mathrm{kg}$ body weight. Normal rats and diabetic rats fed with standard feed without instant aloe vera were used as a control. The animals for each treatment $(n=6)$ were observed for 4 weeks. The amount of instant added to the standard feed was determined by preliminary research based on their reducing power (Yen and Duh, 1994) compared with commercial vitamin $E$ as a standard. The vitamin E contains $\alpha$-tocopherol equivalent to $100 \mathrm{IU}$ per capsule. Intake of instant aloe vera for rats was equalized with the adequate intake of antioxidant to prevent degenerative disorder up to 400 IU/day/adult. Moreover, the value was multiplied by a conversion factor $(0.018)$ to fit the animal feed. The hypoglycemic effect was calculated by the change in blood glucose of diabetic rats before and after being fed with the sample. The rats were fed with the treatment for a period of 4 weeks and blood glucose was analyzed each week using the GOD-PAP method (Goni et al., 1996).

\subsection{Design of experiments}

This study used completely randomized design with the storage time of instant aloe vera as a factor. The differences among the treatments were determined by $\mathrm{F}$ test, and the significant difference between samples was examined by Duncan's Multiples Range Test (DMRT) (Gacula and Singh, 1984).

\section{Results and discussion}

3.1 Phenolic content and antioxidative activity of instant aloe vera

Table 1. Characteristics of instant aloe vera

\begin{tabular}{lc}
\hline \multicolumn{1}{c}{ Characteristics } & $\begin{array}{c}\text { Instant aloe } \\
\text { vera }\end{array}$ \\
\hline RSA (Reactive Scavenging Activity) $(\%)$ & $15.32 \pm 1.14$ \\
Inhibition of lipid peroxidation $(\%)$ & $36.87 \pm 1.58$ \\
Moisture $(\% \mathrm{wb})$ & $5.65 \pm 0.62$ \\
Total phenol $\left(\mu \mathrm{g} / \mathrm{g}\right.$ dry matter) $^{\mathrm{a}}$ & $1.64 \pm 0.09$ \\
\hline
\end{tabular}

${ }^{\mathrm{a}}$ Wariyah and Riyanto, 2015.

Table 1 shows the characteristics of instant aloe 
vera, which related to hypoglycemic effect. The phenolic content of instant aloe vera was $1.64 \pm 0.09 \mu \mathrm{g} / \mathrm{g}$ dry matter and the antioxidative activities which indicated by their RSA (Reactive Scavenging Activity) and the inhibition of lipid peroxidation were $15.32 \pm 1.14 \%$ and $36.87 \pm 1.58 \%$, respectively. Instant aloe vera had a high antioxidant activity, and according to Sultana and Anwar (2008), the antioxidative properties shown by its ability to capture DPPH free radicals. The antioxidative activity could decrease during storage due to contact with heat, oxygen, and light which causes the oxidation of flavonoids (Nawar, 1985). Wariyah and Riyanto (2015) stated that RSA value of instant aloe vera significantly decreased at 5 weeks storage time, while the inhibition of lipid peroxidation decreased after 9 weeks. Therefore, important to study the effect of storage time on the hypoglycemic activity of instant aloe vera.

\subsection{Reducing power of instant aloe vera}

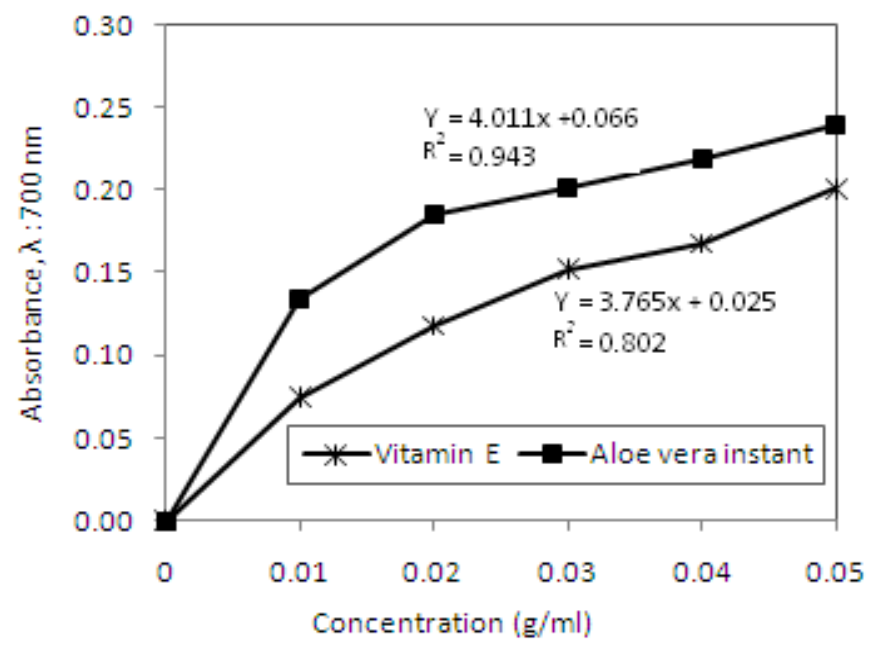

Figure 1. Reducing power of vitamin $\mathrm{E}$ and instant aloe vera.

Reducing the power of instant aloe vera and vitamin $\mathrm{E}$ was compared to determine the rat's intake. Consumption necessary of antioxidant for preventing degenerative disorder is about $400 \mathrm{IU}$ per day, whereas a $0.40 \mathrm{~g}$ capsule of commercial vitamin E containing 100 IU $\alpha$-tocopherol. Therefore, the instant aloe vera given to the rats were equalized with $400 \mathrm{IU} \alpha$-tocopherol in vitamin $\mathrm{E}$ based on their reducing power. The relative reducing power stated by absorbance value is shown in Figure 1. The higher the absorbance, the greater its reducing power or the higher its antioxidative activity as shown by the regression equation of the two samples.

Figure 1 shows the relationship between absorbance and sample weight (instant and vitamin E). The regression equation of vitamin $\mathrm{E}$ is :

$$
\mathrm{y}=4.011 \mathrm{x} \pm 0.066
$$

If the $\mathrm{x}$ parameter is equal to $1.6 \mathrm{~g}$ commercial vitamin $\mathrm{E}$ (equivalent with $400 \mathrm{IU} \alpha$-tocopherol), so the $\mathrm{y}$ parameter $\mathrm{y}=6.4836$. The instant aloe vera regression equation is:

$$
\mathrm{y}=3.765 \mathrm{x} \pm 0.025
$$

To satisfy $y=6.4836$, the instant weight $(x)=1.70$ g. It means that to provide the adequate daily intake of antioxidant about $400 \mathrm{IU} /$ day/adult is needed about 1.70 $\mathrm{g}$ instant aloe vera for a human with a $70 \mathrm{~kg}$ body weight or $0.03 \mathrm{~g}$ for a rat with a $200 \mathrm{~g}$ body weight.

\subsection{Rats body weight and hypoglycemic activity of instant aloe vera}

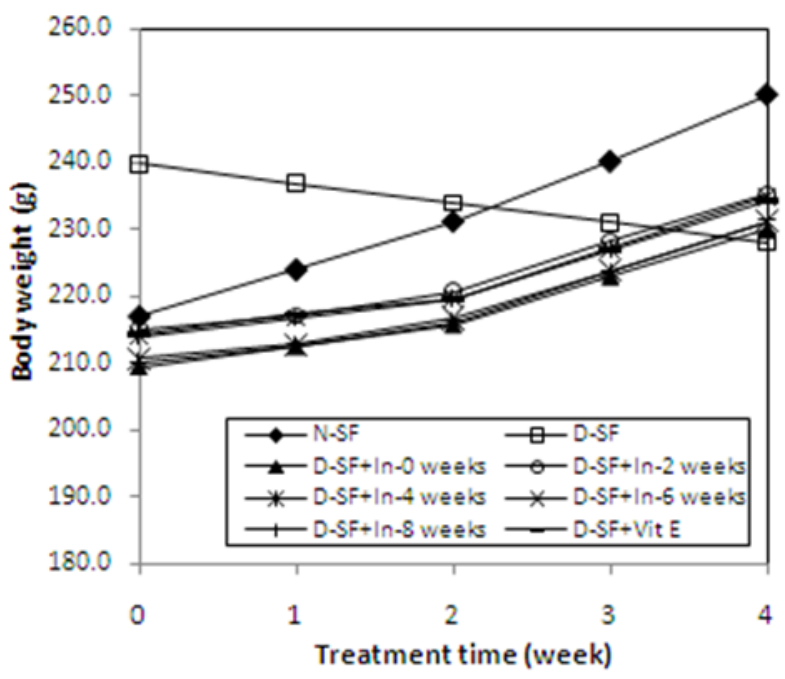

Figure 2. Profile of rat body weight during treatment.

Figure 2 shows the profile of rats body weight during 4 weeks treatment, and Figure 3 shows the rats blood glucose profile with treatment of normal rats fed with standard feed (N-SF), diabetic rats fed with standard feed (D-SF), and diabetic rats fed with standard feed combined with instant aloe vera $(\mathrm{D}-\mathrm{SF} \pm \mathrm{In})$ at various storage time ( 0.0 to 8.0 weeks). Hypoglycemic activity is expressed as the ability of the sample to decrease blood glucose level. The body weight of normal rats fed with standard feed increased during the 4 weeks treatment, while the body weight of diabetic rats with standard feed decreased. Kuzuya et al. (2002) and Al Tera (2011) described that decreasing body weight is one symptom of diabetes mellitus. Diabetic patients undergo weight loss when blood glucose can not be absorbed into the cells and the energy requirement is taken from body fat. Akbarzadeh et al. (2007) found that diabetic rats induced with streptozotocin the body weight decrease in comparison with a normal rat. This study resulted that the body weight of diabetic rats fed with instant aloe vera ( $\mathrm{D}-\mathrm{SF} \pm \mathrm{In}-0$ to 8 weeks) increased with a similar profile in comparison with N-SF. The longer the storage time, the lower increasing of the body weight. 
Figure 3 shows the blood glucose profile of diabetic rats fed with or without instant aloe vera. The diabetic rats fed without an instant aloe vera showed high stable blood glucose $(>200 \mathrm{mg} / \mathrm{dl})$ during the 4 weeks of treatment. Whereas, normal fasting blood glucose was $<110 \mathrm{mg} / \mathrm{dl}$ and $140 \mathrm{mg} / \mathrm{dl}$ after meals (Kuzuya et al., 2002). The blood glucose of diabetic rats fed with instant aloe vera decreased to normal levels by the fourth week of treatment. Winarsi et al. (2014) showed that the diabetic rats given the Ethanolic Cardamon Leaves Extracts (ECLE) which contain flavonoid for 7 consecutive days, decreased in their blood glucose level. Jasmine and Daisy (2007) also stated that the blood glucose of diabetic rats fed with flavonoid extract from Eugenia jambolana for 30 days decreased from 534.60 $\mathrm{mg} / \mathrm{dl}$ to $206.80 \mathrm{mg} / \mathrm{dl}$.

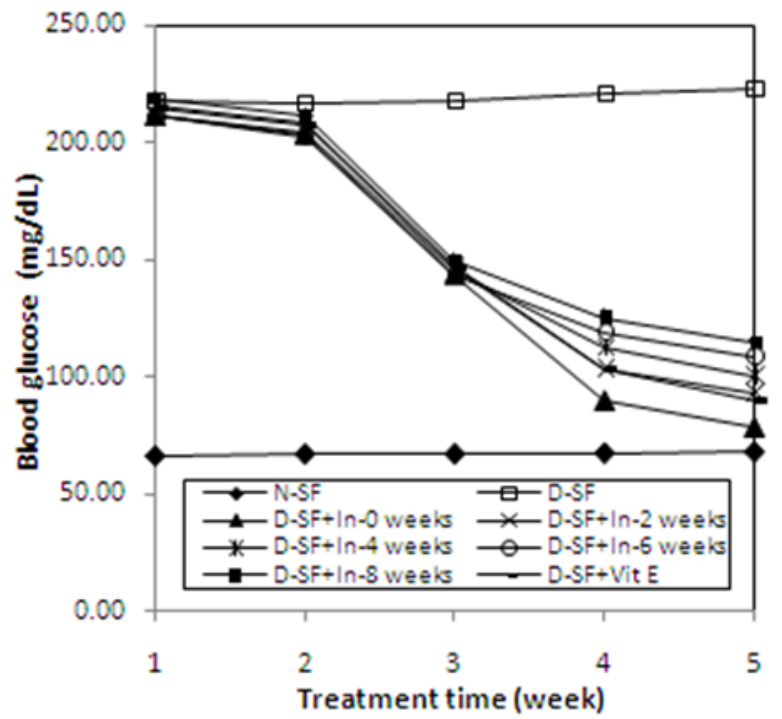

Figure 3. Profile of blood glucose during 4 weeks treatment.

Moreover, flavonoids are capable of stimulating insulin secretion from the pancreas and of excreting an insulin secretion inhibitor. According to Barlett and Eperjesi (2008), hyperglycemia can increase oxidative stress causing an increase of ROS such as superoxide, hydrogen peroxide and singlet oxygen. ROS is capable of damaging lipid membranes, proteins, nucleic acids, and carbohydrates through oxidation, which can result in the formation of cytotoxic chain reactions so that the glucose metabolism is impaired. Increasing of ROS formation leads to more NADH and FADH2 enter to electron transport chain (Suarsana et al., 2011 as cited in Winarsi et al., 2014). The increase of electron transport rate leads to the contribution of free radicals formation and cause a more severe diabetic. Therefore, neutralizing free radicals by use of antioxidants such as the flavonoids found in aloe vera is an important step in decreasing the prevalence of diabetes mellitus.

\section{Conclusion}

Instant aloe vera resulted from microencapsulation of aloe vera powder has hypoglycemic activity. The activity can provide the needed antioxidant to prevent degenerative disorder, especially diabetes mellitus. The hypoglycemic activity of instant aloe vera was affected by the storage time, the longer the storage time, the lower its hypoglycemic activity. The instant aloe vera which packaged in polyethylene plastic with $0.80 \mathrm{~mm}$ thickness until eight weeks and consumed about $0.03 \mathrm{~g}$ for rats or $1.70 \mathrm{~g}$ for human/day could lower blood glucose to the normal level.

\section{Acknowledgements}

We gratefully acknowledge to the Directorate of Research and Community Service, Directorate General of Reinforcement and Development, Ministry of Research, Technology and Higher Education of the Republic of Indonesia, for providing financial support from the Competitive Research Grant Program in 20142015 with research grant agreement letter No. 015/HBLIT/III/2015, March 25, 2015.

\section{References}

Akbarzadeh, A., Norouzian, D., Mehrabi, M.R., Farhangi , A., Allah Verdi, A., Mofidian, S.M.A. and Lame Rad, B. (2007). Induction of diabetes by streptozotocin in rats. Indian Journal of Clinical Biochemistry, 22(2), 60-64.

Al Tera, B.H. (2011). Determinant of non-compliant of diabetes mellitus type 2 (qualitative study in community health centre work area of Srondol, Semarang), Research article, Centre for Nutrition Study, Faculty of Medicine, University of Diponegoro. Semarang. Central Java. Indonesia, p. 10-12. Retrieved on April 11, 2013 from Website: http://

eprints.undip.ac.id/32591/1/393_Banu_Hanifah_Al_ Tera_G2C007014.pdf.

Barlett, H.E. and Eperjesi, F. (2008). Nutritional supplementation for diabetic retinopathy. Ophthal Research Group, School of Life and Health, Aston University, Birmingham. pp. 6-8. Retrieved on March 29, 2015 from Website: http:// eprints.aston.ac.uk/4512/1/Diabetes_\% 26_nutrition_after_review_January.pdf

Gacula M.C. and Singh, J. (1984). Statistical Methods in Food and Consumer Research. London: Academic Press, Inc. 
Goni, I., Garcia-Diz, L., Manas, E. and Saura-Calixso, F. (1996). Analysis of resistant starch: a method for foods and food products, Food Chemistry, 56(4), 445 -449 .

$\mathrm{Hu}$, Q., $\mathrm{Hu}, \mathrm{Y}$. and $\mathrm{Xu}$, J. (2005). Free radicalscavenging activity of aloe vera (Aloe Barbadensis Miller) extracts by supercritical carbon dioxide extraction. Food Chemistry, 91, 85-90.

Jasmine, R. and Daisy, P. (2007). Hypoglycemic and hypolipidemic activity of eugenia jambolana in streptozocin-diabetic rat. Asian Journal of Biochemistry, 2(4), 269-273.

Joseph, B. and Raj, S.J. (2010). Pharmacognostic and Phytochemical Properties of Aloe vera Linn-an overview. International Journal of Pharmaceutical Science Review and Research, 4, 106-110.

Kabir, M., Rizkalla, S.W., Champ, M., Luo, J., Boillot, J., Bruzzo, F. and Slama, G. (1998). Dietary amylose -amylopectin starch content affects glucose and lipid metabolism in adipocytes of normal and diabetic rats. Journal of Nutrition, 128, 35-43.

Kuzuya, T., Nakagawa, S., Satoh, J., Kanazawa, Y., Iwamoto, Y., Kobayashi, M., Nanjo, K., Sasaki, A., Seino, Y., Ito, C., Shima, K., Nonaka, K. and Kadowaki, T. (2002). Report of the committee on the classification and diagnostic criteria of diabetes mellitus. Diabetes Research and Clinical Practice, $55,65-85$.

Nawar, W.W. (1985). Lipids. In Fennema, O.R. (Ed). Food Chemistry, p. 196-198. New York: Marcell Dekker Inc.

Özkan, G. and Bilek, S.E. (2014). Microencapsulation of natural food colourants. International Journal of Nutrition and Food Sciences, 3(3),145-156.

Reeves, P.G., Nielsen F.H. and Fahey, G.C. (1993). AIN -93 Purified diet for laboratory rodents: final report of the American Institute of nutrition ad hoc writing committee on the reformulation of the ain-76a rodent diet. American Institute of Nutrition, 0022.3166, 1939-1951.

Sultana, B. and Anwar, F. (2008). Flavonol (kaempeferol, quercetin, merycetin) contents of selected fruits, vegetables and medicinal plants. Food Chemistry, 108, 879-884.

Wariyah, Ch. and Riyanto. (2015). Shelf life of aloe vera instant and the antioxidative properties during storage, presented at the seminar: technological innovation to strengthen the role of the industry towards the acceleration of the national food fulfillment, Semarang, 2015. Semarang- Indonesia: Indonesian Association of Food Technologists.

Wariyah, Ch. and Riyanto. (2016). Antioxidative activity of microencapsulated aloe vera (Aloe vera var. chinensis) powder with various concentrations of added maltodextrin. International Food Research Journal, 23(2), 537-542.

Wariyah, Ch. and Riyanto. (2011). Effect of drying temperature on antioxidant activity and acceptability of aloe vera (Aloe vera var. chinensis) powder, presented at the International Food Conference: Life improvement through food technology, Surabaya, 2011. Surabaya-Indonesia: Widya Mandala Catholic University.

Winarsi, H., Sasongko, N.D., Purwanto A. and Nuraeni, I. (2014). Effect of cardamom leaves extract as antidiabetic, weight lost and hypocholesterolemic to alloxan-induced Sprague Dawley diabetic rats. International Food Research Journal, 21(6), 2253-2261.

Yagi, A., Hegazy, S., Kabbash, A. and Wahab, E.A.E. (2009). Possible hypoglycemic effect of aloe vera 1. high molecular weight fractions on type 2 diabetic patients. Saudi Pharmaceutical Journal, 17, 209215.

Yen G.C. and Duh, P.D. (1994). Scavenging effect of methanolic extract of peanut hulls on free-radical and active-oxygen species. Journal Agricultural and Food Chemistry, 42, 629-632. 